\title{
A Noncanonical Proximal Heme Ligand Affords an Efficient Peroxidase in a Globin Fold
}

\author{
Moritz Pott, ${ }^{\dagger}\|\|$ Takahiro Hayashi, ${ }^{\dagger, \|}$ Takahiro Mori, ${ }^{\dagger}$ Peer R. E. Mittl, ${ }^{\dagger}$ Anthony P. Green, ${ }^{*, \S \odot}$
} and Donald Hilvert* ${ }^{\dagger} \dagger$

\author{
${ }^{\dagger}$ Laboratory of Organic Chemistry, ETH Zurich, Zurich 8093, Switzerland \\ ${ }^{\ddagger}$ Department of Biochemistry, University of Zurich, Zurich 8057, Switzerland \\ ${ }^{\S}$ School of Chemistry \& Manchester Institute of Biotechnology, The University of Manchester, 131 Princess Street, Manchester \\ M1 7DN, United Kingdom
}

\section{Supporting Information}

ABSTRACT: Expanding the range of genetically encoded metal coordination environments accessible within tunable protein scaffolds presents excellent opportunities for the creation of metalloenzymes with augmented properties and novel activities. Here, we demonstrate that installation of a noncanonical $N_{\delta}$-methyl histidine $(\mathrm{NMH})$ as the proximal heme ligand in the oxygen binding protein myoglobin $(\mathrm{Mb})$ leads to substantial increases in heme redox potential and promiscuous peroxidase activity. Structural characterization of this catalytically modified myoglobin variant (Mb NMH) revealed significant changes in the proximal pocket, including alterations to hydrogen-bonding interactions involving the prosthetic porphyrin cofactor. Further optimization of $\mathrm{Mb}$

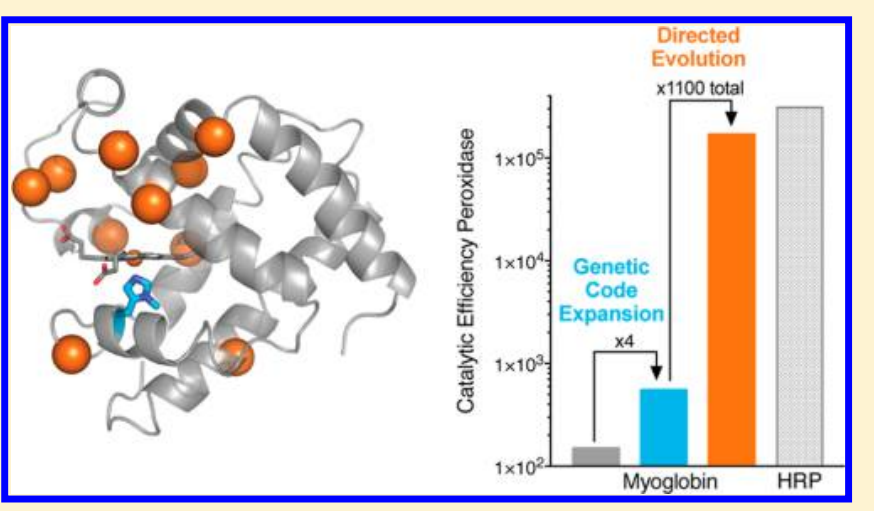
$\mathrm{NMH}$ via a combination of rational modification and several rounds of laboratory evolution afforded efficient peroxidase biocatalysts within a globin fold, with activities comparable to those displayed by nature's peroxidases.

\section{INTRODUCTION}

Heme enzymes are among the most versatile biocatalysts known, promoting a wealth of synthetically useful transformations with high catalytic efficiencies and exacting selectivities. $^{1-3}$ These enzymes provide a striking example of the importance of first coordination ligand environments in dictating the catalytic properties of metalloproteins. The pentacoordinate heme iron systems contain a single genetically encoded proximal ligand, with the remaining four ligands provided by a prosthetic porphyrin cofactor. ${ }^{4}$ The reactivity of individual family members is intimately related to the nature of the proximal ligand as well as secondary interactions of this residue with neighboring amino acids in the proximal pocket. $^{5-11}$ For example, cytochrome P450s and aromatic peroxygenases are characterized by a proximal cysteinate ligand, ${ }^{6,10,11}$ whereas heme peroxidases utilize a histidine residue as the axial ligand, with a strong hydrogen bond formed between the noncoordinating $N_{\delta}$ atom and an aspartate residue that is conserved across the peroxidase family (Figure 1a). ${ }^{5,7-9}$ This aspartate residue is absent in other heme proteins containing axial histidine ligation, including the oxygen binding protein myoglobin, which possesses only low levels of promiscuous peroxidase activity (Figure $1 b$ ). ${ }^{12}$

Heme peroxidases catalyze a range of oxidative transformations using hydrogen peroxide as the terminal oxidant. ${ }^{3}$
The conserved proximal pocket His-Asp hydrogen bond is believed to play a crucial role in controlling the electronic structures and reactivities of the key ferryl-oxo species compounds I and $\mathrm{II},{ }^{5,7-9}$ which have been implicated as common intermediates across a range of heme enzymes (Figure 1c). We recently demonstrated that introduction of a genetically encoded $N_{\delta}$-methyl histidine $(\mathrm{NMH})$ ligand into an engineered ascorbate peroxidase (APX2) leads to a modified enzyme with increased robustness toward irreversible deactivation without compromising catalytic efficiency, despite disrupting the "essential" His-Asp hydrogen-bonding interaction. $^{17}$

Here, we show that introduction of $\mathrm{NMH}$ into myoglobin results in a substantial increase in promiscuous peroxidase activity. Further optimization of this catalytically modified myoglobin via rational modification and several rounds of directed evolution has afforded peroxidase biocatalysts in a globin fold that exhibit catalytic efficiencies approaching those of nature's peroxidase enzymes. More generally, our data demonstrate that tailoring metal coordination environments in "evolvable" protein scaffolds via an expanded genetic code can lead to the creation of biocatalysts with augmented properties.

Received: November 29, 2017

Published: January 8, 2018 


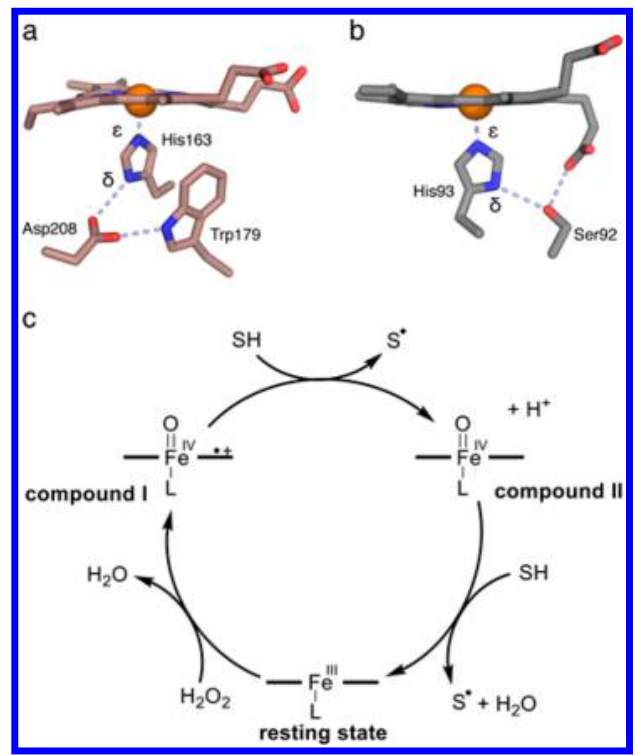

Figure 1. Structure and catalytic mechanism of ascorbate peroxidase and myoglobin. (a) The active site of ascorbate peroxidase (PDB ID: 1OAG). ${ }^{13}$ The His-Asp-Trp motif is also present in cytochrome $c$ peroxidase (CCP), whereas other monofunctional heme peroxidases have a phenylalanine in place of the tryptophan residue. ${ }^{14}$ (b) The active site of sperm whale myoglobin (PDB ID: 1A6K). ${ }^{15}$ (c) Catalytic cycle of the peroxidase-catalyzed substrate (S) oxidation.

\section{RESULTS AND DISCUSSION}

Recombinant Introduction of NMH into Myoglobin. Replacement of the proximal histidine ligand (His93) of sperm whale myoglobin $(\mathrm{Mb})$ with a noncanonical $\mathrm{NMH}$ residue was achieved using an engineered pyrrolysyl-tRNA synthetase/ pyrrolysyl-tRNA ( PylRS $_{\mathrm{NMH}} / \mathrm{tRNA}^{\mathrm{Pyl}}$ ) pair, which selectively encodes $\mathrm{NMH}$ in response to the UAG stop codon. ${ }^{18}$ Coexpression of the required PylRS $\mathrm{NMH}_{\mathrm{N}} / \mathrm{tRNA}^{\mathrm{Pyl}}$ translation components on the pEVOL plasmid ${ }^{19}$ and wild-type swMb (AMBER) on a standard $\mathrm{pET} 29 \mathrm{~b}$ vector led to the production of the desired His93NMH $\mathrm{Mb}$ variant $(\mathrm{Mb} \mathrm{NMH})$, with a protein yield of $>60 \mathrm{mg}$ per liter of culture following purification (Table S1). Stoichiometric replacement of the proximal histidine with $\mathrm{NMH}$ was confirmed by MS analysis of the intact protein (Figure S1).

The UV-vis spectrum of $\mathrm{Mb} \mathrm{NMH}$ in the resting state is almost indistinguishable from that of the wild-type enzyme (Figure 2a). Both variants are characterized by a Soret maximum at $408 \mathrm{~nm}$ with associated $Q$ bands at 503/633 and $541 / 578 \mathrm{~nm}$, consistent with the presence of sixcoordinated high-spin and low-spin heme iron species (Figure $2 \mathrm{a}){ }^{20}$ The heme occupancy of purified $\mathrm{Mb}$ His and $\mathrm{Mb} \mathrm{NMH}$ variants is also very similar, as judged by the ratio of intensities of the bands at 408 and $280 \mathrm{~nm}$. However, replacement of the proximal His ligand by $\mathrm{NMH}$ leads to a substantial increase in heme redox potential $\left(\mathrm{Fe}^{3+} / \mathrm{Fe}^{2+}: \mathrm{Mb} \mathrm{His}+65 \mathrm{mV} ; \mathrm{Mb} \mathrm{NMH}\right.$ $+139 \mathrm{mV}$ ) (Figure S2, Table S2), even though $\mathrm{N}$-methyl-

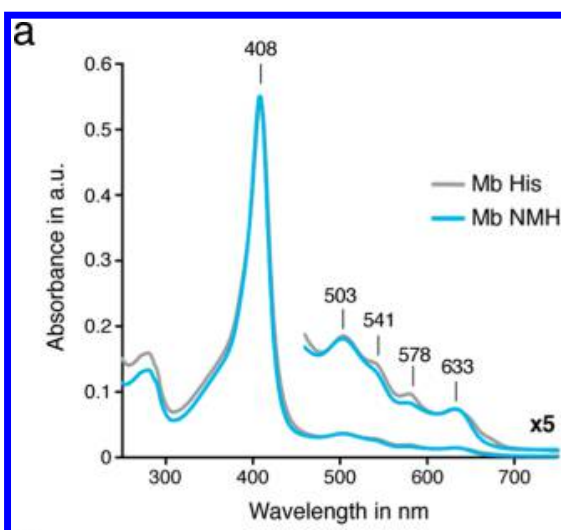

b

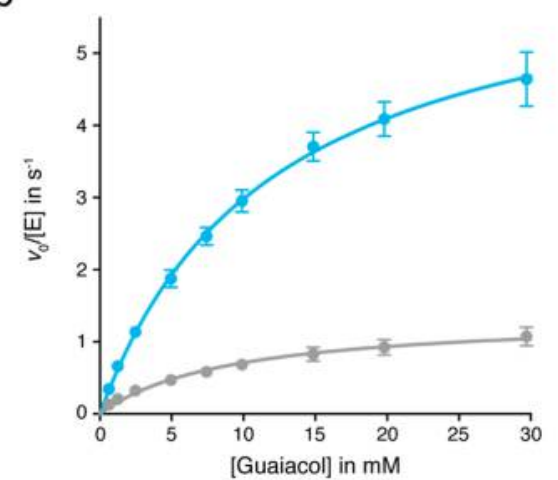

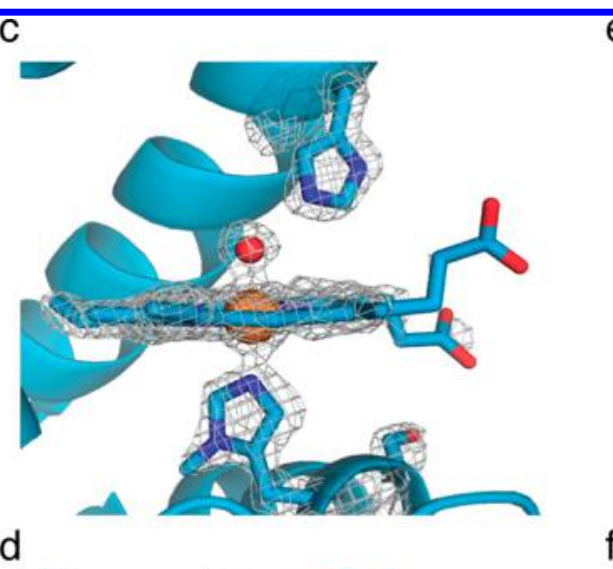

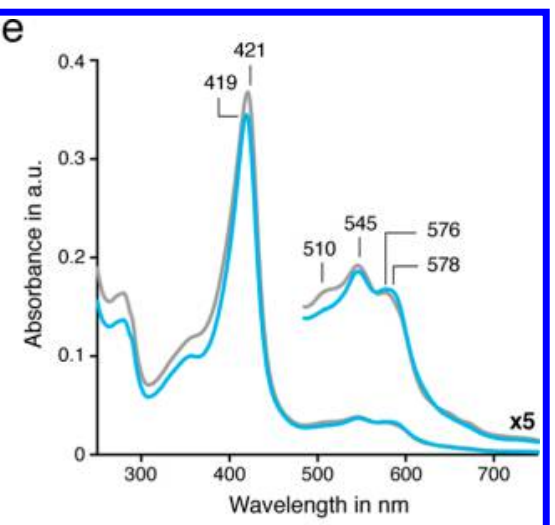

f

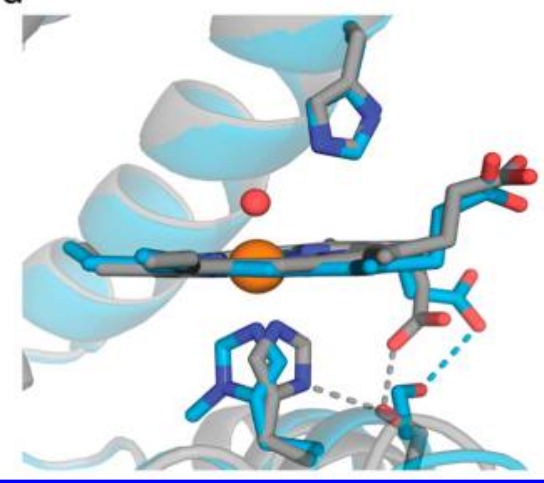

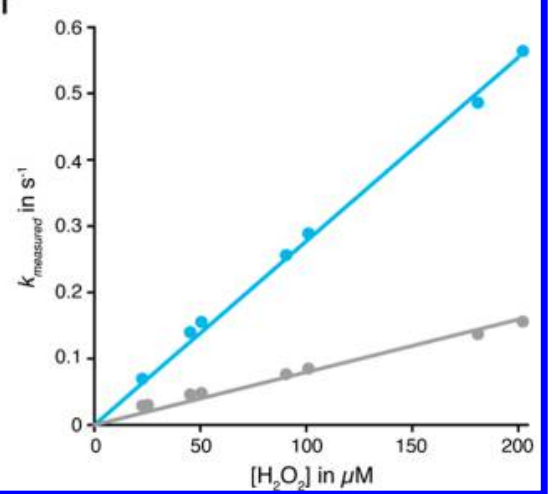

Figure 2. Characterization of $\mathrm{Mb}$ His (gray) and $\mathrm{Mb} \mathrm{NMH}$ (blue). (a) Overlay of the UV-vis spectra of Mb His and Mb NMH in the ferric resting state. (b) Michaelis-Menten kinetics of guaiacol oxidation by $\mathrm{Mb}$ His and $\mathrm{Mb} \mathrm{NMH}$. Formation of the stable tetrameric product was monitored at $470 \mathrm{~nm}^{16}$ (c) Heme binding site of Mb NMH (PDB ID: 5OJ9). The heme cofactor, NMH93, Ser92, and His64 are shown in stick representation. An ordered water molecule (red sphere) is bound to the heme iron (orange) in the distal pocket. Omit maps for the heme cofactor, NMH93, Ser92, and His64, are shown as gray mesh, contoured at 2.5 $\sigma$. (d) Overlay of the active sites of Mb His (gray, PDB ID: 1A6K) ${ }^{15}$ and Mb NMH. (e) Overlay of UV-vis spectra of Mb His and Mb NMH in the ferryl-oxo state. (f) Pseudo first-order kinetics for the formation of the ferryl-oxo intermediate upon treatment of $\mathrm{Mb}$ His and $\mathrm{Mb} \mathrm{NMH}$ with variable concentrations of hydrogen peroxide. 


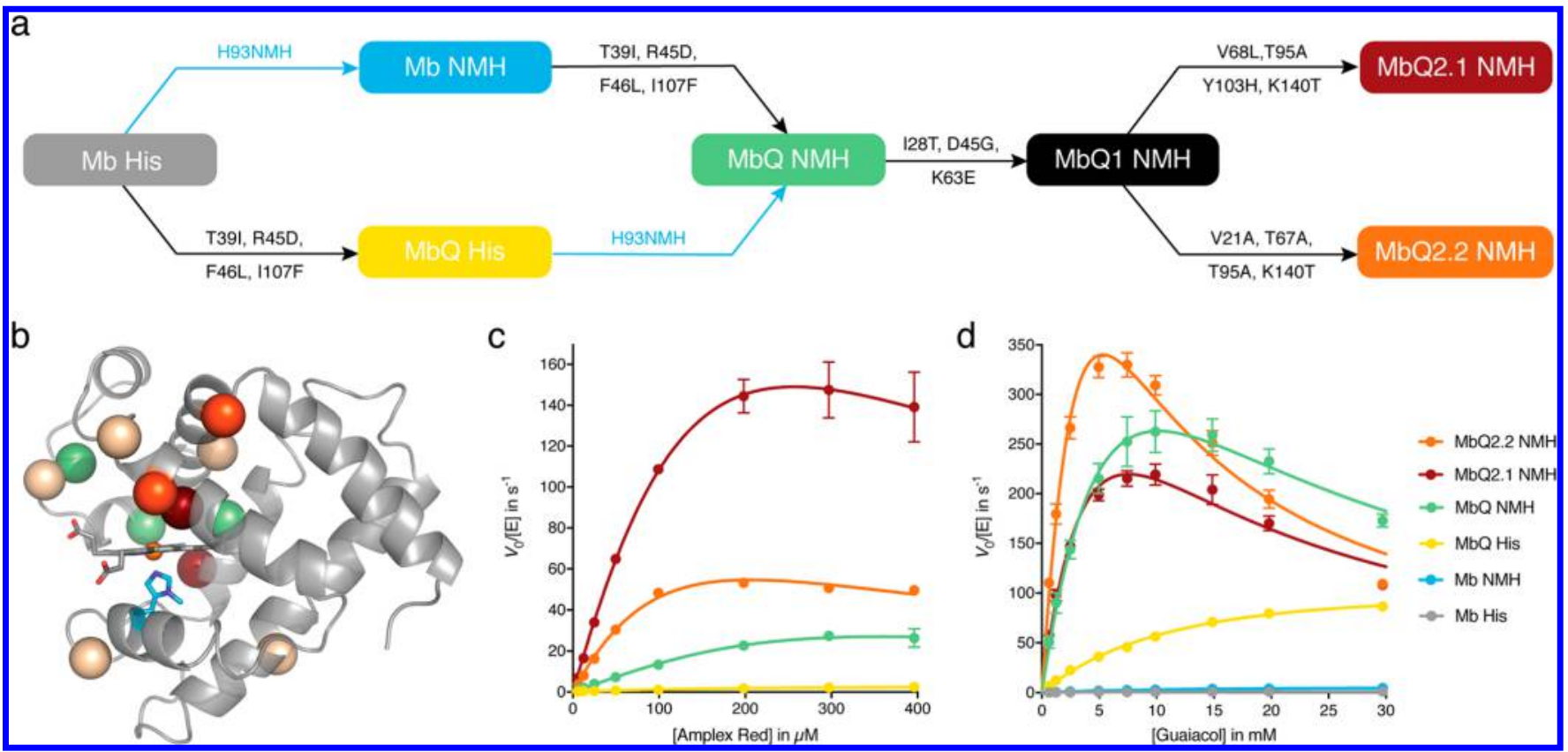

Figure 3. Directed evolution of $\mathrm{Mb} \mathrm{NMH}$ to enhance peroxidase activity. (a) Relationships between the engineered Mb variants. Blue arrows indicate introduction of genetically encoded $\mathrm{NMH}$, whereas black arrows show mutations acquired during optimization. (b) Residues that were altered over the course of evolution are shown as spheres mapped onto the crystal structure of Mb NMH (PDB ID: 5OJ9). Mutations in MbQ $\mathrm{NMH}$ are depicted in green, mutations shared between MbQ2.1 NMH and MbQ2.2 NMH are shown in light brown, and alterations exclusively in $\mathrm{MbQ} 2.2 \mathrm{NMH}$ and MbQ2.1 NMH are shown in orange and dark red, respectively. (c,d) Michaelis-Menten plots for $\mathrm{Mb} \mathrm{His}, \mathrm{Mb} \mathrm{NMH}$, and evolved variants with Amplex Red (c) or guaiacol (d) as substrates.

imidazole has a $\mathrm{p} K_{\mathrm{a}}$ slightly higher than that of imidazole (7.38 versus 7.18$)^{21}$

The crystal structure of $\mathrm{Mb} \mathrm{NMH}$ was solved and refined to a resolution of $1.48 \AA$ (Figure 2c, Table S3). This structure superimposes well with a previously reported $\mathrm{Mb}$ His structure, with little movement of the peptide backbone (Figure $2 \mathrm{~d}$, rootmean-square deviation (rmsd) of $0.35 \AA$ for the superposition on $1 \mathrm{~A} 6 \mathrm{~K}){ }^{15}$ The $\mathrm{N}-\mathrm{Fe}$ distance to the coordinating $\mathrm{NMH}$ axial ligand is $2.10 \AA$, as compared to the value of $2.14 \AA$ reported previously for $\mathrm{Mb}$ His in its resting state. ${ }^{15}$ An ironbound water in the distal pocket is also well ordered, with an $\mathrm{Fe}-\mathrm{O}$ distance of $2.25 \AA$. More striking differences were found in the proximal pocket: the $N$-methyl imidazole ring is rotated by $100^{\circ}$ with respect to the imidazole in the wild-type enzyme (Figure 2d). In addition, Ser92, which is hydrogen-bonded to both the $N_{\delta}$ of the axial His ligand and the heme propionate group in the wild-type structure, now points away from the axial NMH ligand and forms a hydrogen bond exclusively with the propionate group. The $74 \mathrm{mV}$ increase in heme redox potential is presumably ascribable to the loss of this hydrogen bond in combination with the greater hydrophobicity of the $\mathrm{N}$ methyl group..$^{22,23}$ Additionally, the hydrogen bond between the heme-propionate group and the $N_{\varepsilon}$ atom of His 97 observed in wild-type $\mathrm{Mb}$ His is disrupted in $\mathrm{Mb} \mathrm{NMH}$, with both residues adopting altered conformations in the NMHmodified variant.

Kinetic Characterization. $\mathrm{Mb}$ His and $\mathrm{Mb} \mathrm{NMH}$ catalyze the oxidation of $o$-methoxyphenol (guaiacol) by hydrogen peroxide. The reaction affords a stable tetrameric product whose formation can be readily monitored by absorbance at $470 \mathrm{~nm} .{ }^{16,24}$ Kinetic parameters were determined for both variants in the presence of $10 \mathrm{mM}$ hydrogen peroxide.

Introduction of a proximal $\mathrm{NMH}$ ligand results in a 3.7 -fold increase in $k_{\text {cat }} / K_{\mathrm{M}}$, with values of $150 \pm 10$ versus $550 \pm 20$
$\mathrm{M}^{-1} \mathrm{~s}^{-1}$ determined for $\mathrm{Mb}$ His and $\mathrm{Mb} \mathrm{NMH}$, respectively (Figure 2b, Table S4). Thus, the introduction of a single, noncanonical active site substitution leads to a substantial enhancement in catalytic efficiency, dominated by an increase in the $k_{\text {cat }}$ term $\left(1.4\right.$ vs $\left.6.6 \mathrm{~s}^{-1}\right)$. The analogous His $\rightarrow \mathrm{NMH}$ substitution in APX2 led to a $\sim 2$-fold reduction in $k_{\text {cat }}{ }^{17}$ The improved kinetic parameters for $\mathrm{Mb} \mathrm{NMH}$ versus $\mathrm{Mb}$ His are accompanied by a small increase in total turnover number (TTN) achieved prior to enzyme deactivation, with TTNs of $140 \pm 10$ and $180 \pm 30$ observed for $\mathrm{Mb}$ His and $\mathrm{Mb} \mathrm{NMH}$, respectively.

The UV-vis spectra of the ferryl-oxo intermediates of $\mathrm{Mb}$ His and $\mathrm{Mb} \mathrm{NMH}$, recorded following mixing of the resting enzymes with hydrogen peroxide in the absence of the phenolic substrate (Figure 2e), exhibited only minor differences. However, a significant increase in the presteady-state rate constant $\left(k_{\mathrm{obs}}\right)$ for formation of this species was observed: $\mathrm{Mb}$ His $\left(k_{\text {obs }}=800 \pm 60 \mathrm{M}^{-1} \mathrm{~s}^{-1}\right)$ and $\mathrm{Mb} \mathrm{NMH}\left(k_{\text {obs }}=2770 \pm\right.$ $120 \mathrm{M}^{-1} \mathrm{~s}^{-1}$ ) (Figure 2f, Table S5). Consistent with previous studies on myoglobin, ${ }^{25-27}$ the typical porphyrin $\pi$ cation radical intermediate (compound $\mathrm{I}$ ) seen in natural peroxidases (Figure 1c) did not accumulate in $\mathrm{Mb} \mathrm{NMH}$, and a single transition to a neutral ferryl-oxo heme species (compound II) was seen. Attempts to detect compound I by addition of lower concentrations of peroxide (1.0-5.0 equiv) were unsuccessful, and led to incomplete conversion to compound II with no evidence of compound I accumulation.

The relative stability of compound $\mathrm{II}$ in $\mathrm{Mb} \mathrm{His}$ and $\mathrm{Mb}$ $\mathrm{NMH}$ was also investigated. Autoreduction of compound II to the ferric state, which likely occurs by oxidation of nearby aromatic amino acid side chains, was monitored in a doublemixing stopped-flow experiment involving treatment of the resting enzymes with an excess of $\mathrm{H}_{2} \mathrm{O}_{2}$, followed by decomposition of unreacted peroxide with catalase. Substitu- 
tion of the proximal His ligand with $\mathrm{NMH}$ led to only minor changes in compound II stability, with $k_{\text {auto }}$ values of $7.1 \times 10^{-3}$ and $5.2 \times 10^{-3} \mathrm{~s}^{-1}$ for $\mathrm{Mb}$ His and $\mathrm{Mb} \mathrm{NMH}$, respectively (Figure S3, Table S6).

Optimization of $\mathrm{Mb} \mathrm{NMH}$ via Rational Modification and Laboratory Evolution. To enhance the peroxidase activity of $\mathrm{Mb} \mathrm{NMH}$, we initially introduced four point mutations near the active site (T39I, R45D, F46L, I107F) (Figures 3a,b and S4) that were previously shown to enhance the promiscuous peroxidase activity of wild-type $\mathrm{Mb}$ while preserving the distal histidine at position $64 .{ }^{12}$ The resulting MbQ NMH variant was characterized by a further $\sim 140$-fold increase in catalytic efficiency as compared to $\mathrm{Mb} \mathrm{NMH}$, with $k_{\text {cat }}=840 \pm 190 \mathrm{~s}^{-1}, K_{\mathrm{M}}=11 \pm 3 \mathrm{mM}$, and $k_{\text {cat }} / K_{\mathrm{M}}=7.5 \times 10^{4}$ $\mathrm{M}^{-1} \mathrm{~s}^{-1}$. Significantly, the catalytic efficiency of MbQ NMH is substantially higher $(\sim 7.1$-fold $)$ than the corresponding His ligated variant $\mathrm{MbQHis}\left(k_{\mathrm{cat}}=120 \pm 3 \mathrm{~s}^{-1}, K_{\mathrm{M}}=12 \pm 1 \mathrm{mM}\right.$, and $\left.k_{\text {cat }} / K_{\mathrm{M}}=1.1 \times 10^{4} \mathrm{M}^{-1} \mathrm{~s}^{-1}\right)$, demonstrating that the beneficial impact of installing the noncanonical NMH proximal ligand is even greater following optimization of the protein sequence to enhance peroxidase activity. Under pre-steady-state conditions, the four point mutations also increase the rates of compound II formation $\left(k_{\mathrm{obs}}=(7.4 \pm 0.9) \times 10^{4}\right.$ and $(2.1 \pm$ $0.2) \times 10^{4} \mathrm{M}^{-1} \mathrm{~s}^{-1}$ for MbQ NMH and MbQHis, respectively) (Figure S5, Table S5) and compound II autoreduction ( $k_{\text {auto }} 1.1$ $\times 10^{-1}$ and $4.8 \times 10^{-2} \mathrm{~s}^{-1}$ for MbQ NMH and MbQ His, respectively) (Figure S3, Table S6).

Directed evolution was employed to further improve the $\mathrm{Mb}$ variant containing the noncanonical NMH residue. To that end, we exploited an established assay for peroxidase activity based on Amplex Red oxidation to evaluate individual variants as crude cell-lysates arrayed in 96-well plates. ${ }^{28} \mathrm{MbQ} \mathrm{NMH}$ also catalyzes the oxidation of Amplex Red with increased efficiency and served as the template for laboratory evolution. Screening of two successive error-prone libraries and a third library created by shuffling of selected beneficial mutations (Figure 3a,b) afforded the variant MbQ2.1 NMH, which contains seven additional amino acid substitutions (I28T, D45G, K63E, V68L, T95A, Y103H, K140T) (Figure S6). The locations of the mutations installed during evolution are shown in Figure 3b. One of the mutated residues, Tyr103, was previously shown to form irreversible cross-links with the heme cofactor upon generation of transient phenoxy radicals during catalysis. $^{29,30}$ Despite mutation of this readily oxidized residue, attempts to isolate compound I in MbQ2.1 NMH, or indeed in any of the engineered $\mathrm{Mb}$ variants, were unsuccessful.

MbQ2.1 NMH is characterized by a 10 -fold increase in Amplex oxidation efficiency as compared to $\mathrm{MbQ} \mathrm{NMH}$ (Figure 3c), with a $k_{\text {cat }} / K_{\mathrm{M}}$ value of $1.5 \times 10^{6} \mathrm{M}^{-1} \mathrm{~s}^{-1}\left(k_{\mathrm{cat}}=\right.$ $690 \pm 340 \mathrm{~s}^{-1}$ and $K_{\mathrm{M}}=460 \pm 270 \mu \mathrm{M}$ ), which is $\sim 50$-fold higher than wild-type ascorbate peroxidase (APX) and only $\sim 5$ fold lower than horseradish peroxidase (HRP) (Figure S7 and Table S8). A second variant, MbQ2.2 NMH (V21A, I28T, D45G, K63E, T67A, T95A, K140T vs MbQ NMH) (Figures $3 \mathrm{a}, \mathrm{b}$ and S6), which exhibited activity comparable to that of MbQ2.1 NMH under lysate assay conditions (Table S9), proved to be the superior variant for guaiacol oxidation, with a $k_{\text {cat }} / K_{\mathrm{M}}$ value of $1.7 \times 10^{5} \mathrm{M}^{-1} \mathrm{~s}^{-1}\left(k_{\mathrm{cat}}=1400 \pm 340 \mathrm{~s}^{-1}\right.$ and $K_{\mathrm{M}}=8.3 \pm 2.6 \mathrm{mM}$ ), which represents an $\sim 2.2$-fold increase over MbQ NMH and an $\sim 1140$-fold increase over $\mathrm{Mb}$ His (Figure 3d). The catalytic efficiency of MbQ2.2 NMH is superior to that of wild-type APX ( $\sim 13$-fold) and is only slightly lower than HRP ( 1.8-fold) (Figure S7 and Table S4).
Comparison of the kinetic parameters of $\mathrm{Mb}$ His, $\mathrm{Mb} \mathrm{NMH}$, and the engineered variants reveals strong correlations between the $k_{\text {cat }}$ of guaiacol oxidation and (1) the rate of compound II formation ( $k_{\text {obs, }}$, Table S5, Figures $2 \mathrm{f}, \mathrm{S5}$, and S9) and (2) compound II reactivity ( $k_{\text {auto }}$, Table S6 and Figures S3 and S9). Judging from the $K_{\mathrm{M}}$ values, optimization through rational modification and evolution appears not to have altered substrate binding substantially. Significantly, the improvements in catalytic efficiency observed throughout the progression from $\mathrm{Mb}$ His to the most evolved $\mathrm{NMH}$-containing variants is also manifest in substantially improved TTNs prior to irreversible deactivation (Figure 4). In particular, high TTNs were

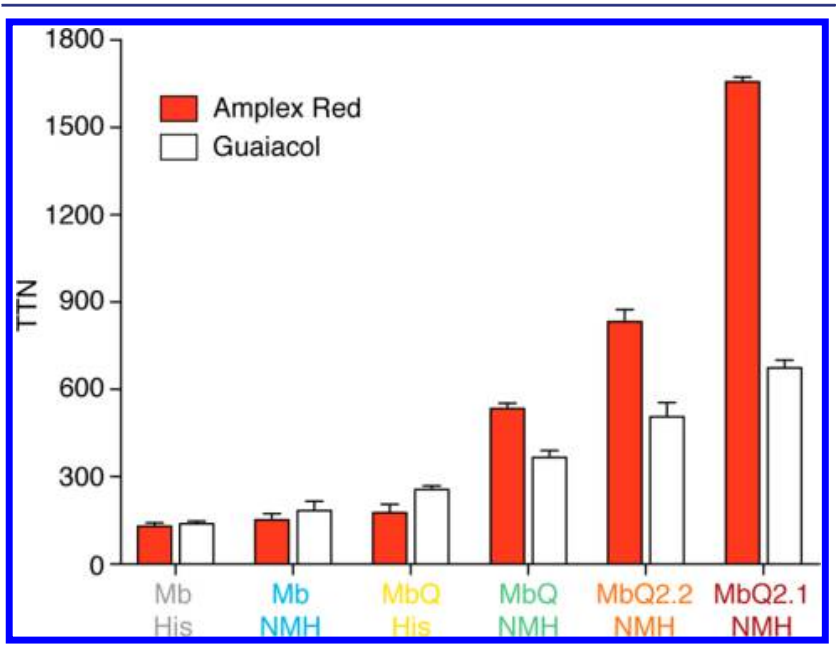

Figure 4. Total turnover numbers (TTNs) performed by $\mathrm{Mb} \mathrm{His}, \mathrm{Mb}$ $\mathrm{NMH}$, and evolved variants for the oxidation of Amplex Red (red) and guaiacol (white) prior to irreversible deactivation.

observed with MbQ2.1 NMH, which may be attributed to the removal of readily oxidizable Tyr103 adjacent to the heme. Notably, the rate of compound II autoreduction in MbQ2.1 $\mathrm{NMH}\left(k_{\text {auto }}=6.3 \times 10^{-2} \mathrm{~s}^{-1}\right)$ is also significantly lower than those in MbQ NMH $\left(k_{\text {auto }}=1.1 \times 10^{-1} \mathrm{~s}^{-1}\right)$ and MbQ2.2 $\mathrm{NMH}\left(k_{\text {auto }}=1.4 \times 10^{-1} \mathrm{~s}^{-1}\right)$.

Substrate Scope. To investigate substrate scope, the activities of the engineered $\mathrm{Mb} \mathrm{NMH}$ variants toward oxidation of a set of electron-rich aromatics were determined at a single substrate concentration (Figure 5). For all substrates tested, introduction of the genetically encoded $\mathrm{NMH}$ ligand resulted in increased initial velocities, with the exception of $p$-cresol for which a slightly reduced rate was observed with $\mathrm{Mb} \mathrm{NMH}$ versus $\mathrm{Mb}$ His. This single active site substitution led to a substantial 8.9-fold increase in activity toward 2,6-dimethoxyphenol. Significantly, further optimization of the protein sequence through a combination of point mutations (MbQ $\mathrm{NMH}$ ) and directed evolution (MbQ2.1 NMH and MbQ2.2 $\mathrm{NMH}$ ) yielded variants with significantly enhanced activity toward all assayed substrates.

Structural Analysis. The crystal structures of MbQ His, $\mathrm{MbQ} \mathrm{NMH}$, and MbQ2.1 NMH, refined to a resolution of $1.35,1.54$, and $1.25 \AA$, respectively (Table S3 and Figure S10), superimpose well with the $\mathrm{Mb}$ and $\mathrm{Mb} \mathrm{NMH}$ structures, and show that mutations introduced during evolution cause only minor changes in overall protein fold ( $\mathrm{rmsds}$ of $0.4-0.6 \AA$ for the superposition on $\mathrm{Mb}$ and $0.3-0.6 \AA$ for the superposition on $\mathrm{Mb} \mathrm{NMH}$ ). The His and $\mathrm{NMH}$ proximal ligands adopt conformations almost identical to those observed in $\mathrm{Mb}$ His 


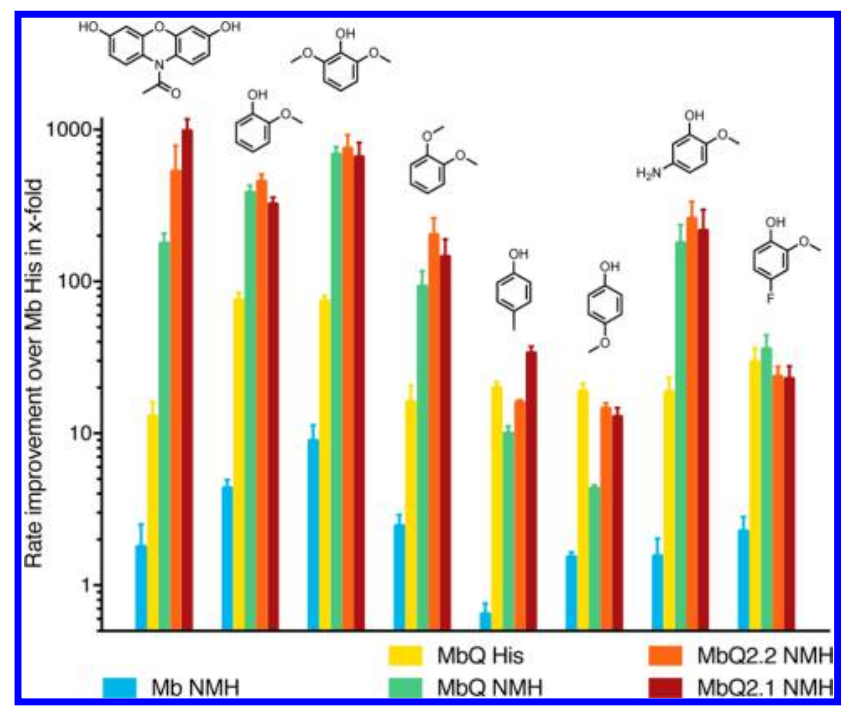

Figure 5. Substrate scope of $\mathrm{Mb} \mathrm{NMH}$ and engineered variants. Improvements in initial rates relative to wild-type $\mathrm{Mb}$ are reported for the oxidation of a panel of electron-rich aromatic substrates.

and $\mathrm{Mb} \mathrm{NMH}$. All three structures show an exogenous imidazole ligand in the distal pocket that coordinates the heme iron. In MbQ2.1 NMH, the Thr95Ala mutation shortens the proximal helix supporting the axial NMH ligand by one residue due to loss of the hydrogen bond between the Thr95 hydroxyl group and the carbonyl of Gln91. Consequently, the adjacent loop is extended and adopts an altered conformation, with a new hydrogen bond formed between His97 and Asp44 (Figure 6). Interestingly, the heme cofactor in MbQ His, MbQ NMH, and MbQ2.1 NMH is bound in a "flipped" conformation ${ }^{31,32}$ as compared to $\mathrm{Mb}$ His and $\mathrm{Mb} \mathrm{NMH}$, which alters the

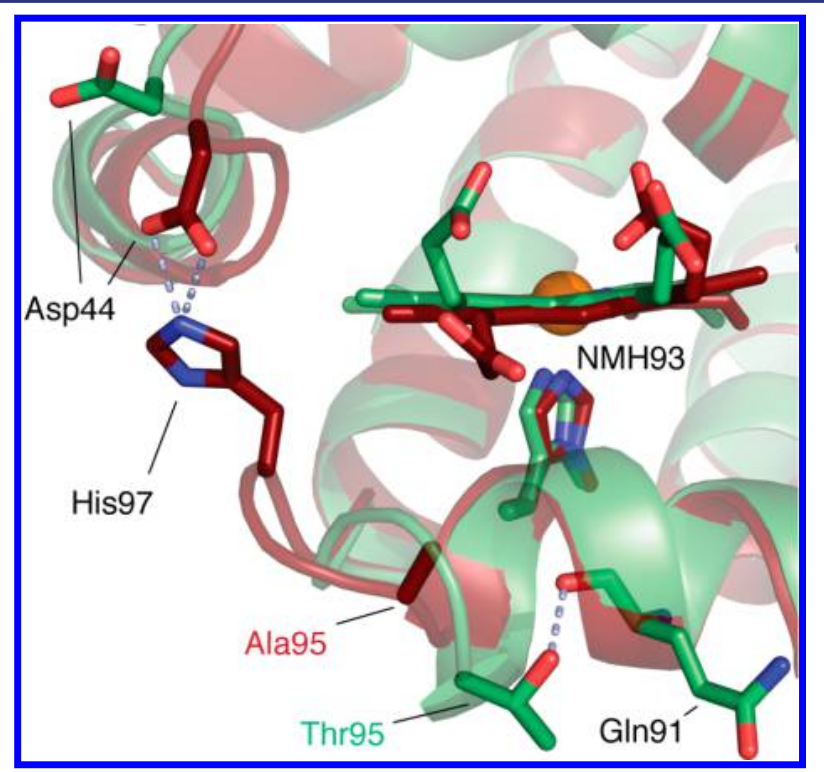

Figure 6. Structural changes following directed evolution of $\mathrm{MbQ}$ $\mathrm{NMH}$. Overlay of the crystal structures of MbQ NMH (green, PDB ID: 5OJB) and MbQ2.1 NMH (red, PDB ID: 5OJC) illustrating the shortening of the proximal helix due to Thr95Ala mutation, the extension and conformation change of the neighboring loop, and the formation of a new hydrogen bond between Asp44 and His97. Key residues and the heme cofactor are shown in stick representation, and the iron center is shown as a sphere. positioning of the heme vinyl substituents within the protein template.

\section{CONCLUSION}

Nature employs a limited number of genetically encoded proximal ligands to control the plethora of versatile reactivities displayed by heme enzymes. ${ }^{1,4}$ Considerable effort has been devoted to unraveling the relationships between proximal pocket coordination environment and heme enzyme function, an endeavor that continues to be an area of intensive debate and investigation..$^{5-11,33}$ For example, the ability of cytochrome $\mathrm{P} 450$ s to functionalize unactivated $\mathrm{C}-\mathrm{H}$ bonds is dependent upon the axial cysteine ligation. Strong electron donation from the thiolate ligand increases the basicity of compound II $\left(\mathrm{p} K_{\mathrm{a}} \approx\right.$ 12) to afford a protonated $\mathrm{Fe}(\mathrm{IV})-\mathrm{OH}$ intermediate, which is believed to provide the driving force for $\mathrm{C}-\mathrm{H}$ activation. $^{11,33-35}$ In contrast, compound II of histidine-ligated hemes in peroxidases and globins is significantly less basic, and is most often described as $\mathrm{Fe}(\mathrm{IV})=\mathrm{O}$ species. ${ }^{36-40}$

The ability to expand upon nature's genetically encoded residues to introduce noncanonical proximal ligands into heme enzymes offers a potentially powerful approach to probe enzyme mechanism and to create modified enzymes with augmented properties. For example, cysteine to selenocysteine substitutions in several cytochrome $\mathrm{P} 450 \mathrm{~s}$ have revealed important insights into the relationship between electron donation from the proximal ligand and P450 reactivity. ${ }^{41-45}$ We have recently extended this approach by replacing the proximal histidine ligand of a peroxidase with a noncanonical structural analogue. Introduction of a genetically encoded $\mathrm{NMH}$ ligand into APX2 overcomes the reliance on the proximal pocket His-Asp hydrogen-bonding interaction, which is conserved across the peroxidase family. ${ }^{17}$ As compared to the parent enzyme, APX2 NMH is characterized by an increased robustness toward irreversible deactivation and only a $\sim 2$-fold reduction in $k_{\text {cat }}$.

In the present study, we have explored the effects of the analogous His $\rightarrow \mathrm{NMH}$ substitution in myoglobin, an oxygen binding heme protein that possesses low levels of peroxidase activity and that lacks the Asp-His hydrogen-bonding interaction characteristic of a natural peroxidase. Myoglobin has served as a valuable model system to probe heme enzyme structure-function relationships, and combinations of structure-guided active site substitutions and laboratory evolution have afforded engineered variants with diverse catalytic functions. ${ }^{26,46-49}$ Introduction of the noncanonical $\mathrm{NMH}$ into $\mathrm{Mb}$ increases the redox potential of the heme center $\left(\mathrm{Fe}^{3+} / \mathrm{Fe}^{2+}: \mathrm{Mb}\right.$ His $\left.+65 \mathrm{mV}: \mathrm{Mb} \mathrm{NMH}+139 \mathrm{mV}\right)$ as well as the promiscuous peroxidase activity ( $\sim 4$-fold for guaiacol oxidation). This result appears counterintuitive, because natural heme peroxidases are characterized by a significantly lower redox potential than myoglobin. ${ }^{50}$ This unexpected trend serves to highlight the difficulties in comparing structure-activity relationships across heme protein families.

The enormous rate enhancements provided by peroxidases have been attributed to highly evolved and complex networks of active site residues. For example, strong electron donation from the proximal ligand is accompanied by sophisticated arrangements of catalytically important amino acids in the distal heme pocket, which are believed to play key roles in promoting peroxide $\mathrm{O}-\mathrm{O}$ bond heterolysis and in proton delivery to the ferryl oxygen during rate-limiting compound II reduction processes. ",9,51 The "imidazolate-like" character of the proximal 
ligand likely raises the basicity of the ferryl-oxo intermediates, while a conserved peroxidase distal His residue is ideally positioned (distance between $N_{\varepsilon}$ and ferric heme iron is 6.0 and $5.6 \AA$ in $\mathrm{HRP}^{52}$ and $\mathrm{CCP},{ }^{53}$ respectively) to mediate key proton transfer events. The analogous distal His64 residue in myoglobin is significantly closer to the heme iron (4.3 $\AA$ ), which restricts its ability to serve as proton donor/acceptor in the peroxidase catalytic cycle. ${ }^{54,55}$

Further optimization of $\mathrm{Mb} \mathrm{NMH}$ via rational modification (MbQ NMH) and laboratory evolution (MbQ2.1 NMH and $\mathrm{MbQ} 2.2 \mathrm{NMH}$ ) has led to the creation of efficient peroxidase biocatalysts in a globin fold, with activities comparable to nature's peroxidases. It is tempting to speculate that the origins of enhanced activity lie in the evolution of altered catalytic mechanisms, which more closely resemble those of natural peroxidases. The redox potentials of the engineered variants, while substantially higher than for natural peroxidases, are lower than for $\mathrm{Mb} \mathrm{NMH}(+139 \mathrm{mV})$, with values of $+80,+65$, and $+56 \mathrm{mV}$ determined for MbQ NMH, MbQ2.1 NMH, and MbQ2.2 NMH, respectively. The reduction in redox potential is accompanied by increased rates of compound II formation and increased reactivity of this species, as evidenced by higher rates of substrate oxidation and autoreduction processes (likely due to electron transfer from nearby amino acid side chains).

It is possible that the increased susceptibility of compound II to reduction arises from an increased basicity of the ferryl oxygen, combined with the evolution of a more effective mechanism for proton delivery, which is required to generate the $\mathrm{Fe}(\mathrm{III})-\mathrm{OH}$ state. The Arg45 residue, which is postulated to restrict motion of distal His64 residue in wild-type myoglobin, ${ }^{56}$ was mutated first to aspartate and then to glycine during the course of evolution. Because X-ray crystal structures of the engineered $\mathrm{Mb}$ variants all show an exogenous imidazole ligand in the distal pocket coordinating the heme iron, the His64 $N_{\varepsilon}-\mathrm{Fe}$ bond distances in the apo enzyme are uncertain. Facile displacement of His64 may indicate increased conformational flexibility of this residue, potentially enabling transient adoption of more productive conformations during catalysis.

At the current stage of optimization, significant differences between the catalytic mechanisms of natural peroxidases and engineered globins remain evident. This is highlighted by the relative catalytic performances of $\mathrm{MbQ} \mathrm{His}$ and $\mathrm{MbQ} \mathrm{NMH}$. Here, introduction of the NMH ligand still provides a substantial increase in activity despite being seemingly less electron donating in the context of the proximal binding pocket. The increased reactivity of compound II in MbQNMH is associated with an increased redox potential, and thus can be attributed to a greater driving force for electron transfer to the ferryl heme. In contrast, compound II reduction in natural peroxidases likely proceeds through a proton coupled electron transfer mechanism, which facilitates efficient electron transfer despite low redox potentials. ${ }^{51}$ The early rounds of $\mathrm{Mb} \mathrm{NMH}$ optimization were accompanied by reductions in redox potential, and it will be interesting to see whether subsequent rounds of evolution deliver globin catalysts with redox potentials more akin to those of nature's peroxidases.

In depth biophysical, structural, and kinetic studies will be required to fully unravel the origins of improved catalytic performance in our engineered myoglobins. However, what is clear from the present study is that expanding the repertoire of amino acid substitutions beyond those available through traditional site-directed mutagenesis can provide valuable chemical probes of enzyme mechanism. Our study also highlights how powerful directed evolution protocols can be readily adapted to allow optimization of modified enzymes containing noncanonical active site functionality. More generally, we demonstrate that the installation of new metal coordination environments into tunable protein templates can lead to the generation of modified enzymes with augmented properties, laying the foundation for future studies aimed at the creation of "chemically programmed" metalloenzymes capable of promoting synthetically useful "nonbiological" reactions with the high catalytic efficiencies and exacting selectivities associated with nature's enzymes.

\section{EXPERIMENTAL PROCEDURES}

Materials. All chemical and biological reagents were purchased from commercial suppliers and used without further purification. LB medium and 2xYT were purchased from MP Biomedicals, LLC (CA) and Sigma-Aldrich (MO). Hemin chloride and 30\% hydrogen peroxide were purchased from Merck Millipore (Darmstadt, Germany), $\delta$-aminolevulinic acid from Acros Organics (Geel, Belgium), PBS ( $\mathrm{pH}$ 7.4) from Gibco (ThermoFisher Scientific, MA), guaiacol, PEG1500, horse radish peroxidase (HRP), bovine liver catalase, and lysozyme from Sigma-Aldrich (MO), H-His(3-Me)-OH (NMH) from Bachem (Bubendorf, Switzerland), polymyxin B from Panreac AppliChem (Darmstadt, Germany), DNase I from Roche Diagnosis GmbH (Mannheim, Germany), and Amplex Red from Chemodex (St. Gallen, Switzerland). Phusion High-Fidelity DNA polymerase, T4 DNA ligase, and all restriction enzymes used in this study were purchased from New England BioLabs (MA). The JBS error-prone PCR kit was purchased from Jena Bioscience (Jena, Germany). Oligonucleotides were synthesized by Microsynth AG (Balgach, Switzerland).

Physical and Biophysical Measurements. UV-vis absorption spectra were acquired on a Lamda 35 spectrophotometer (PerkinElmer, MA). Fast protein liquid chromatography (FPLC) was carried out on an NGC Quest 10 plus chromatography system (Bio-Rad laboratories, CA) equipped with a multiwavelength detector, BioFrac fraction collector, and a Superdex 75 increase 10/300 GL (GE healthcare Life Sciences, IL) size exclusion (SEC) column. Sodium dodecyl sulfate-polyacrylamide gel electrophoresis (SDS-PAGE) was performed on a PhastSystem electrophoresis apparatus using precast PhastGel homogeneous 20.0 (GE healthcare Life Sciences). Highresolution mass spectra were recorded on an electrospray ionization quadrupole time-of-flight (ESI-Q-TOF) system MaXis (Bruker Daltonics, Bremen, Germany) coupled with an Agilent 1200 system (Agilent technology, CA). Steady-state and pre-steady-state stoppedflow experiments were performed on an Applied Photophysics SX18 stopped-flow spectrophotometer (Applied Photophysics Ltd., Leatherhead, UK) equipped with a xenon arc lamp and a $1 \mathrm{~cm}$ path length.

Construction of pET29_Mb, pET29_Mb H93NMH, and Variants. A gene encoding wild-type sperm whale $\mathrm{Mb}$ was ligated into a pET29b(+) vector between the NdeI and XhoI restriction sites, yielding pET29b_Mb. The His93NMH mutation was introduced into the pET29b_Mb by replacing the His93 codon with a TAG stop codon. Two fragments corresponding to the $\mathrm{N}$ and $\mathrm{C}$ termini were synthesized with the primer pairs $\mathrm{Mb} N \mathrm{NdeI}(+)$ and $\mathrm{Mb} \_$His93NMH(-), Mb_His93NMH(+) and $\mathrm{Mb}_{-}{ }_{-} \mathrm{XhoI}(-)$ (Table $\mathrm{S} 10 \overline{)}$. The two PCR products were purified and then combined in an equimolar ratio for the final PCR. The full length fragment was assembled using the primer pair $\mathrm{Mb} \_N d e \mathrm{I}(+)$ and $\mathrm{Mb} \_X h o \mathrm{I}(-)$. The mutated fragment was digested by ${ }^{-} \mathrm{NdeI}, \mathrm{XhoI}$ and ligated into a pET29b(+) vector digested with the same restriction enzymes, yielding pET29b Mb His93NMH. The quartet mutations (T39I, R45D, F46L, I107F) were introduced into the pET29b_Mb and pET29b Mb His93NMH by overlap extension PCR. Three fragments were synthesized with the primer pairs $\mathrm{Mb} \_\mathrm{NdeI}(+)$ and $\mathrm{Q} 1(-)$, $\mathrm{Q} 1(+)$ and $\mathrm{Q} 2(-), \mathrm{Q} 2(+)$ and $\mathrm{Mb} X \mathrm{Xho}(-)$ (Table S10). The three PCR products were purified and then combined in an equimolar ratio for the final PCR. The full length fragments were assembled using 
the primer pair $\mathrm{Mb} \mathrm{NdeI}(+)$ and $\mathrm{Mb} X h o \mathrm{I}(-)$. The mutated fragment was digested by NdeI, XhoI and ligated into pET29b(+) as described above. DNA sequence was confirmed by the DNA sequencing service provided by Microsynth AG.

Protein Production and Purification. For expression of $\mathrm{Mb}$, $\mathrm{MbQ}$ and APX, pET29b Mb and pET29b APX were used to individually transform BL21-Gold(DE3) E. coli. Transformed cells were plated onto an $\mathrm{LB}$ agar plate containing $50 \mu \mathrm{g} / \mathrm{mL}$ kanamycin. A single colony of freshly transformed cells was cultured for $6 \mathrm{~h}$ in $3 \mathrm{~mL}$ of LB medium containing $50 \mu \mathrm{g} / \mathrm{mL}$ kanamycin. $1.6 \mathrm{~mL}$ of the culture was used to inoculate $160 \mathrm{~mL}$ of $2 \mathrm{xYT}$ medium supplemented with 1 $\mathrm{mM} \delta$-aminolevulinic acid and $50 \mu \mathrm{g} / \mathrm{mL}$ kanamycin. The culture was incubated for $\sim 2 \mathrm{~h}$ at $37^{\circ} \mathrm{C}$ with shaking at $230 \mathrm{rpm}$. When the $\mathrm{OD}_{600}$ of the culture reached $\sim 0.5$, IPTG was added to a final concentration of $1 \mathrm{mM}$. For expression of $\mathrm{Mb} \mathrm{NMH}$, BL21-Gold(DE3) E. coli was cotransformed with pET29b_Mb His93NMH and pEVOL_PylRS $_{\mathrm{NMH}}{ }^{18}$ and the cells were plated onto an LB agar plate containing $50 \mu \mathrm{g} / \mathrm{mL}$ kanamycin and $34 \mu \mathrm{g} / \mathrm{mL}$ chloramphenicol. A single colony of freshly transformed cells was cultured for $6 \mathrm{~h}$ in $3 \mathrm{~mL}$ of LB medium containing $50 \mu \mathrm{g} / \mathrm{mL}$ kanamycin and $34 \mu \mathrm{g} / \mathrm{mL}$ chloramphenicol. $1.6 \mathrm{~mL}$ of the culture was used to inoculate $160 \mathrm{~mL}$ of $2 \mathrm{xYT}$ medium supplemented with $1 \mathrm{mM} \delta$-aminolevulinic acid, 12 $\mathrm{mM}$ H-His(3-Me)-OH (NMH), $50 \mu \mathrm{g} / \mathrm{mL}$ kanamycin, and $34 \mu \mathrm{g} / \mathrm{mL}$ chloramphenicol. The culture was incubated for $\sim 2.5 \mathrm{~h}$ at $37^{\circ} \mathrm{C}$ with shaking at $230 \mathrm{rpm}$. When the $\mathrm{OD}_{600}$ of the culture reached $\sim 0.5$, IPTG and L-arabinose were added to a final concentration of $1 \mathrm{mM}$ and $0.02 \%$, respectively. The same procedure was used to produce $\mathrm{MbQ} \mathrm{NMH}, \mathrm{MbQ} \mathrm{NMH}$ 2.1, and MbQ 2.2. The induced cultures were incubated for $\sim 20 \mathrm{~h}$ at $25^{\circ} \mathrm{C}$, and the cells were subsequently harvested by centrifugation at $2137 \mathrm{~g}$ for $20 \mathrm{~min}$. The pelleted bacterial cells were suspended in Tris- $\mathrm{HCl}$ buffer $(50 \mathrm{mM}$ Tris- $\mathrm{HCl}, 300 \mathrm{mM}$ $\mathrm{NaCl}, \mathrm{pH}$ 8.0). To maximize heme occupancy, $\mathrm{Mb}$ and $\mathrm{Mb} \mathrm{NMH}$ variants were reconstituted with hemin chloride. Briefly, cell suspensions were mixed with $0.32 \mathrm{mM}$ of hemin chloride $(20 \mathrm{mM}$ stock solution in $10 \mathrm{mM} \mathrm{NaOH}$ ) prior to sonication. Cell lysates were centrifuged at $15000 \mathrm{~g}$ for $20 \mathrm{~min}$, and the supernatants were subjected to affinity chromatography using Ni-NTA Agarose (Qiagen, Helden, Germany). His-tagged $\mathrm{Mb}$ variants were eluted by $50 \mathrm{mM}$ Tris-HCl, $300 \mathrm{mM} \mathrm{NaCl}$ at pH 7.4 containing $300 \mathrm{mM}$ imidazole. The $\mathrm{Mb}$ and $\mathrm{Mb} \mathrm{NMH}$ solutions were then subjected to SEC on Superdex 75 increase $10 / 300 \mathrm{GL}$ at a flow rate of $0.9 \mathrm{~mL} / \mathrm{min}$ using an NGC Quest 10 plus FPLC system equilibrated with PBS. The fractions were monitored at 260,280, and $408 \mathrm{~nm}$, collected using a BioFrac fraction collector, and analyzed by SDS-PAGE. If necessary, the protein solution was concentrated by Amicon Ultra- 15 10-kDa cutoff centrifugal filter device (Merck Millipore, MA). The concentrations of heme-containing proteins were determined assuming an extinction coefficient of $188000 \mathrm{M}^{-1} \mathrm{~cm}^{-1}$ at $408 \mathrm{~nm}$ for $\mathrm{Mb}$ and its variants ${ }^{57}$ and $88000 \mathrm{M}^{-1} \mathrm{~cm}^{-1}$ at $403 \mathrm{~nm}$ for APX.58

MS Analysis of $\mathrm{Mb}$ and $\mathrm{Mb}$ NMH Variants. MS data for $\mathrm{Mb}$ and $\mathrm{Mb}$ NMH were acquired on an ESI-Q-TOF system coupled with an Agilent 1200 system. Protein solutions were desalted by Zeba spin desalting column (ThermoFisher Scientific, MA) equilibrated with pure water containing $0.1 \%$ acetic acid. The final protein concentrations were adjusted to $10 \mu \mathrm{M}$. The MS instrument was operated in wide pass quadrupole mode with the TOF data being collected between $\mathrm{m} / z \quad 100-5000$ with low-collision energy of $8 \mathrm{eV}$. The optimized source conditions were drying gas $8.0 \mathrm{~L} \mathrm{~h}^{-1}$ (nitrogen $99.99 \%$ purity) at a temperature of $200{ }^{\circ} \mathrm{C}$, nebulizer pressure $1.6 \mathrm{bar}$, capillary and end plate voltages 500 and $4500 \mathrm{~V}$, respectively, TOF flight tube voltage $9880 \mathrm{~V}$, reflection voltage $2004 \mathrm{~V}$, pusher voltage $1640 \mathrm{~V}$, and MCP detector voltage $2927 \mathrm{~V}$. The ESI-TOF mass spectrometer was calibrated routinely for flow injection analysis (FIA) in the positive electrospray ionization mode using Agilent-ESI-TOF tuning mix on the enhanced quadratic algorithmic mode. Further data processing was performed using the Data Analysis 4.1 software (Bruker Daltonics) with deconvolution software MaxEnt (Spectrum Square Associates, U.S.).

Spectroscopic Characterization of $\mathrm{Mb}$ and $\mathrm{Mb} \mathrm{NMH}$ Variants. UV-vis absorption spectra of $\mathrm{Mb}$ and $\mathrm{Mb} \mathrm{NMH}$ variants in the resting states were recorded on a Lamda 35 spectrophotometer in PBS buffer at a final concentration of $2-5 \mu \mathrm{M}$. UV-vis absorption spectra of ferryl-oxo species were recorded following the addition of $\mathrm{H}_{2} \mathrm{O}_{2}(200 \mu \mathrm{M}$ final concentration) to a solution of $\mathrm{Mb}(3 \mu \mathrm{M})$ or $\mathrm{Mb}$ NMH $(3 \mu \mathrm{M})$ in PBS buffer. Spectra were recorded on a UV-vis spectrophotometer equilibrated to $25^{\circ} \mathrm{C}$.

Redox Potential Measurements. Reduction potentials were determined using the method of Raven et al. ${ }^{59}$ In brief, a buffered solution $(50 \mathrm{mM}$ potassium phosphate buffer, $\mathrm{pH} 7.0)$ containing xanthine as a source of electrons $(300 \mu \mathrm{M})$, protein $(\sim 3 \mu \mathrm{M}$, to give an absorbance of $\sim 0.5)$, and a suitable dye (toluidine blue $\left(E_{\mathrm{mT}}=+34\right.$ $\mathrm{mV}$ ) for $\mathrm{Mb}$ His, MbQ His, MbQ NMH, MbQ2.1 NMH, MbQ2.2 $\mathrm{NMH}$, and toluylene blue $\left(E_{\mathrm{mT}}=+115 \mathrm{mV}\right)$ for $\left.\mathrm{Mb} \mathrm{NMH}\right)$ was added to a quartz cuvette. The cuvette was sealed with a septum, and the solution was made anaerobic by nitrogen flow. Following the addition of xanthine oxidase ( $50 \mathrm{nM}$ final concentration), absorbance changes corresponding to reduction of the heme and/or dye were measured in a range of $350-750 \mathrm{~nm}$. Spectra were collected at $25.0^{\circ} \mathrm{C}$ every $15 \mathrm{~s}$ to 2 min over a period of $\sim 300 \mathrm{~min}$ after the addition of xanthine oxidase (a fast scan rate is needed for optimum results and to ensure consistency of concentration determinations at different wavelengths). Once a constant absorbance reading was achieved, a few specks of sodium dithionite were added at the end of the reaction to obtain an absorbance reading for the fully reduced protein. Data were fitted to a Nernst plot. All potentials are reported versus a normal hydrogen electrode (NHE).

Stopped-Flow Kinetics. $\mathrm{Mb}$ and APX variants were diluted to $800 \mathrm{nM}$ (commercial HRP to $50 \mathrm{nM}$ ) on the basis of the heme absorption $\left(\mathrm{Mb}^{57} \varepsilon_{408}=188000 \mathrm{M}^{-1} \mathrm{~cm}^{-1}\right.$; APX, ${ }^{58} \varepsilon_{403}=88000 \mathrm{M}^{-1}$ $\mathrm{cm}^{-1}$; HRP, $\left.{ }^{60} \varepsilon_{403}=100000 \mathrm{M}^{-1} \mathrm{~cm}^{-1}\right)$ in PBS. Substrate solutions containing 1.25, 2.5, 5.0,10,15,20,30,40, and $60 \mathrm{mM}$ guaiacol or $12.5,25,50,100,200,400,600,800 \mu \mathrm{M}$ Amplex Red and $20 \mathrm{mM}$ $\mathrm{H}_{2} \mathrm{O}_{2}$ were prepared in PBS and used immediately. Solutions were loaded into the stopped-flow UV-vis spectrometer equilibrated to 25 ${ }^{\circ} \mathrm{C}$. Product formation was monitored by the change in absorbance at $470 \mathrm{~nm}$ for guaiacol $\left(\varepsilon_{470}=22000 \mathrm{M}^{-1} \mathrm{~cm}^{-1}\right)$ and $571 \mathrm{~nm}$ for Amplex Red $\left(\varepsilon_{571}=58000 \mathrm{M}^{-1} \mathrm{~cm}^{-1}\right)$. Typically, $2-5$ shots were averaged, and the averaged traces were fitted by linear regression using Prism7. The observed initial rates were fitted to the Michaelis-Menten equation. If necessary, the Michaelis-Menten equation was modified to account for substrate inhibition.

Pseudo first-order rate constants for the formation of the $\mathrm{Mb}$ ferryloxo species were obtained as follows. Briefly, one syringe of the stopped-flow apparatus containing $5 \mu \mathrm{M}$ enzyme in PBS was mixed with the other containing at least a 10 -fold excess of $\mathrm{H}_{2} \mathrm{O}_{2}(50,100$, 200 , and $400 \mu \mathrm{M}$ ) in the same buffer. Ferryl-oxo species formation was monitored by an increase in absorbance at $430 \mathrm{~nm}$. The second-order rate constants were extracted from the slope of the plots. Reported values are the average of two individual measurements.

The decay rate of the ferryl-oxo species was determined in double mixing stopped-flow experiments. To that end, $12 \mu \mathrm{M}$ protein was mixed 1:1 with $400 \mu \mathrm{M} \mathrm{H}_{2} \mathrm{O}_{2}$ in PBS at $25^{\circ} \mathrm{C}$. The mixture was aged until the respective protein reached full conversion to the ferryl-oxo state (60 s Mb His, $15 \mathrm{~s} \mathrm{Mb} \mathrm{NMH,} 2 \mathrm{~s}$ MbQ His, $1 \mathrm{~s} \mathrm{MbQ} \mathrm{NMH,} 1.5$ $\mathrm{s}$ MbQ2.1 NMH, $1 \mathrm{~s} \mathrm{MbQ2.2} \mathrm{NMH)} \mathrm{before} \mathrm{being} \mathrm{mixed} \mathrm{1:1} \mathrm{with} 500$ $\mathrm{nM}$ bovine liver catalase to degrade any excess $\mathrm{H}_{2} \mathrm{O}_{2}$. Spectra were recorded with a photodiode array, the decay of the ferryl-oxo species was monitored by an increase in absorbance at $405 \mathrm{~nm}$, and the resulting time traces were fitted to a single exponential to derive autoreduction rates.

Total Turnover Number (TTN) Determination. All reactions were carried out at $25{ }^{\circ} \mathrm{C}$ in PBS with $50 \mathrm{nM}$ freshly purified protein and $10 \mathrm{mM} \mathrm{H}_{2} \mathrm{O}_{2}$. Reactions with Amplex Red were carried out with $600 \mu \mathrm{M}$ substrate, and the TTNs were determined after $20 \mathrm{~min}$ relative to a control reaction in the absence of enzyme. For guaiacol, reactions were performed with $2.5 \mathrm{mM}$ substrate. Product formation was monitored spectrophotometrically at $470 \mathrm{~nm}$ to the point of maximal turnover. The values reported are the average of three independent measurements. 
Substrate Scope. Reactions were carried out at $25{ }^{\circ} \mathrm{C}$ in PBS buffer in a stopped flow apparatus as described above, using final concentrations of $10 \mathrm{mM} \mathrm{H}_{2} \mathrm{O}_{2}, 400 \mathrm{nM}$ enzyme, and $10 \mathrm{mM}$ substrate for all substrates except Amplex Red $(200 \mu \mathrm{M})$ and 5aminoguaiacol $(1 \mathrm{mM})$. Product formation was monitored by the change in absorbance (330 nm for $p$-cresol and p-methoxyphenol; 440 $\mathrm{nm}$ for 1,2-dimethoxybenzene; $470 \mathrm{~nm}$ for guaiacol, 4-fluoro-2methoxyphenol, 2,6-dimethoxyphenol, and 5-aminoguaiacol; $571 \mathrm{~nm}$ for Amplex Red). The initial rates of the reactions catalyzed by the $\mathrm{Mb}$ variants were normalized to those of $\mathrm{Mb}$ His. Results depicted in Figure 5 originate from three independent measurements.

Crystallization and Structure Determination. $\mathrm{Mb} \mathrm{NMH}$ in PBS buffer was concentrated to approximately $30-45 \mathrm{mg} / \mathrm{mL}$ by Amicon Ultra-15 $10-\mathrm{kDa}$ cutoff centrifugal filter device. The protein solution was passed through a Zeba spin desalting column preequilibrated with pure water, and the final concentration was adjusted to $30 \mathrm{mg} / \mathrm{mL}$. The protein was crystallized by vapor diffusion in sitting drops at $20{ }^{\circ} \mathrm{C}$. An initial crystallization hit was identified in a well containing $0.1 \mathrm{M}$ SPG buffer at $\mathrm{pH} 7$ containing 25\% (w/v) PEG1500 by using a commercial sparse matrix screen, the PACT Suite (Qiagen). Crystallization conditions were improved by varying the buffer $\mathrm{pH}$ and the concentration of PEG1500. The optimal crystallization condition was $0.1 \mathrm{M}$ succinic acid, sodium dihydrogen phosphate, glycine (SPG) buffer at $\mathrm{pH} 6.8-7.2$ containing $28-32 \%$ (w/v) PEG1500. Crystallization of $\mathrm{MbQ}$ MbQ NMH, and MbQ NMH 2.1 was also achieved under these conditions. Crystals were cryoprotected by plunging into mother liquor supplemented with $20 \%(\mathrm{w} / \mathrm{v})$ glycerol prior to flash freezing in liquid nitrogen. Diffraction data were collected at $100 \mathrm{~K}$ using a wavelength of $1.00 \AA$ at the Swiss Light Source (SLS) X06SA PX beamline. Maximum resolution of diffraction was estimated according to the literature. ${ }^{61}$ The structure was solved by molecular replacement with MOLREP using the myoglobin structure (PDB ID: 5C6Y) for $\mathrm{Mb} \mathrm{NMH}$ and the resulting structure (PDB ID: 5OJ9) for all other variants. The structure was further refined using the programs REFMAC5 ${ }^{62}$ and COOT. ${ }^{63}$ Refinement statistics are summarized in Table S3. The rmsd values were calculated using Pymol. The crystal structures of $\mathrm{Mb}$ variants were deposited in the RCSB Protein Data Bank (PDB) under accession numbers $\mathrm{Mb}$ $\mathrm{NMH}, 5 \mathrm{OJ9}$; MbQ His, 5OJA; MbQ NMH, 5OJB; and MbQ2.1 $\mathrm{NMH}, 5 \mathrm{OJC}$.

MbQ NMH Library Construction and Selection. Libraries were created by error prone PCR using pET29b_MbQ His93NMH (round 1) and pET29b_MbQ.1 His93NMH (round 2) as templates, with primer pair $\mathrm{Mb}{ }_{-}{ }_{-} \mathrm{NdeI}(+)$ and $\mathrm{Mb} \_$XhoI $(-)$(Table S10) using Jena Bioscience Error-Prone Kit according to the manufacturer's protocol. PCR conditions were adjusted to generate an average of 2.3 amino acid changes in round 1 and 2.8 in round 2. The resulting PCR fragments were digested with XhoI, NdeI and ligated into the pET29b vector digested with the same restriction enzymes.

Electro-competent BL21-Gold(DE3) E. coli cells were cotransformed with the ligated libraries and $\mathrm{pEVOL} \mathrm{PyIRS}_{\mathrm{NMH}}$. Five single clones were sequenced to estimate the mutation rate of the library. Per round, 704 freshly transformed clones were used to inoculated $170 \mu \mathrm{L}$ of LB medium supplemented with $50 \mu \mathrm{g} / \mathrm{mL}$ kanamycin and $34 \mu \mathrm{g} /$ $\mathrm{mL}$ chloramphenicol distributed over eight 96-well microtiter plates. As a reference, 6 freshly transformed single clones of the parent template (pET29b MbQ His93NMH in round 1 and pET29b_MbQ.1 His93NMH in round 2) were included on each plate. Plates were incubated overnight at $37^{\circ} \mathrm{C}, 100 \%$ humidity on a shaking incubator at $900 \mathrm{rpm}$. Five microliters of the overnight cultures was transferred to $170 \mu \mathrm{L}$ of $2 \mathrm{xYT}$ medium supplemented with $12 \mathrm{mM} \mathrm{NMH}, 1 \mathrm{mM} \delta$-aminolevulinic acid, $50 \mu \mathrm{g} / \mathrm{mL}$ kanamycin, and $34 \mu \mathrm{g} / \mathrm{mL}$ chloramphenicol. These cultures were incubated for $1.5 \mathrm{~h}$ at $37^{\circ} \mathrm{C}, 100 \%$ humidity on a shaking incubator at $900 \mathrm{rpm}$, at which time gene expression was induced by the addition of L-arabinose and IPTG at final concentrations of $0.02 \%$ and $1 \mathrm{mM}$, respectively.

Expression was carried out for $20 \mathrm{~h}$ at $25^{\circ} \mathrm{C}, 100 \%$ humidity, 900 rpm. Subsequently, cells were pelleted by centrifugation at $2147 \mathrm{~g}, 4$ ${ }^{\circ} \mathrm{C}$, for $15 \mathrm{~min}$, and the supernatant was discarded. Cell pellets were subjected to three freeze-thaw cycles prior to resuspension in PBS supplemented with $1 \mathrm{mg} / \mathrm{mL}$ lysozyme, $0.3 \mathrm{mg} / \mathrm{mL}$ polymyxin $\mathrm{B}$, and incubation for $1 \mathrm{~h}$ at room temperature. Cell debris was removed by centrifugation at $2147 \mathrm{~g}, 20 \mathrm{~min}$ at room temperature. For screening, $50 \mu \mathrm{L}$ of clarified cell lysate was transferred to black 96-well fluorescence plates, and reactions were initiated by the addition of $150 \mu \mathrm{L}$ of PBS containing Amplex Red (50 $\mu \mathrm{M}$ final concentration) and $\mathrm{H}_{2} \mathrm{O}_{2}$ (1 mM final concentration). Formation of the resorufin product was monitored by fluorescence emission at $590 \mathrm{~nm}$ (excitation wavelength $530 \mathrm{~nm}$ ). Reaction rates and total turnover of individual variants were normalized to the average of the 6 parent clones included as controls.

The 20-30 most active "hits" (showing at least a 25\% improvement over parent) from each round were streaked out from the overnight culture onto LB agar plates supplemented with $50 \mu \mathrm{g} / \mathrm{mL}$ kanamycin and $34 \mu \mathrm{g} / \mathrm{mL}$ chloramphenicol. Expression and screening was repeated ( $3 \times$ for each variant) to verify the initial data. Plasmids of the 10 best variants were isolated and sequenced. Identified hits contained on average 2.4 amino acid changes in round 1 and 1.8 in round 2 . The nine most promising mutations from round 2 were shuffled using mutagenic primers oMoP243, oMoP251-oMoP257 (Table S10) and external primers $\mathrm{Mb} \_N d e \mathrm{I}(+), \mathrm{Mb} \_X h o \mathrm{I}(-)$ in an overlap extension PCR, with subsequent cloning and transformation as described above. 704 single clones (ensuring 1.4-fold coverage of theoretical library size) were evaluated as described above. Finally, hits $\mathrm{MbQ} 2.1 \mathrm{NMH}$ and MbQ2.2 $\mathrm{NMH}$ were expressed on larger scale, purified, and subjected to detailed kinetic characterization (see above).

\section{ASSOCIATED CONTENT}

\section{Supporting Information}

The Supporting Information is available free of charge on the ACS Publications website at DOI: 10.1021 jacs.7b12621.

MS data, UV-vis spectral data, kinetic analysis, and structure statistics (PDF)

\section{AUTHOR INFORMATION}

\section{Corresponding Authors}

*anthony.green@manchester.ac.uk

*hilvert@org.chem.ethz.ch

ORCID ${ }^{\circ}$

Anthony P. Green: 0000-0003-0454-1798

Donald Hilvert: 0000-0002-3941-621X

Author Contributions

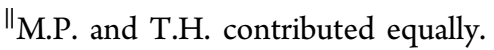

Notes

The authors declare no competing financial interest.

\section{ACKNOWLEDGMENTS}

We are grateful to C. Stutz-Ducommun and B. Blattmann for help in protein crystallization, and the beamline staff at the Swiss Light Source for support during data collection. This research was generously supported by the ETH Zurich, the Swiss National Science Foundation (D.H.), a JSPS fellowship (T.H.), the Biotechnology and Biological Sciences Research Council (David Phillips Fellowship BB/M027023/1, A.P.G.), and the UK Catalysis Hub funded by the EPSRC (grants EP/ K014706/2, EP/K014668/1, EP/K014854/1, EP/K014714/1, and EP/M013219/1, A.P.G.).

\section{REFERENCES}

(1) Brandenberg, O. F.; Fasan, R.; Arnold, F. H. Curr. Opin. Biotechnol. 2017, 47, 102-111.

(2) Urlacher, V. B.; Eiben, S. Trends Biotechnol. 2006, 24, 324-330. 
(3) van Rantwijk, F.; Sheldon, R. A. Curr. Opin. Biotechnol. 2000, 11, 554-564.

(4) Poulos, T. L. Chem. Rev. 2014, 114, 3919-3962.

(5) Goodin, D. B. JBIC, I. Biol. Inorg. Chem. 1996, 1, 360-363.

(6) Krest, C. M.; Silakov, A.; Rittle, J.; Yosca, T. H.; Onderko, E. L.;

Calixto, J. C.; Green, M. T. Nat. Chem. 2015, 7, 696-702.

(7) Poulos, T. L. JBIC, L. Biol. Inorg. Chem. 1996, 1, 356-359.

(8) Poulos, T. L. Arch. Biochem. Biophys. 2010, 500, 3-12.

(9) Raven, E. L. Nat. Prod. Rep. 2003, 20, 367-381.

(10) Rittle, J.; Green, M. T. Science 2010, 330, 933-937.

(11) Wang, X.; Ullrich, R.; Hofrichter, M.; Groves, J. T. Proc. Natl. Acad. Sci. U.S.A. 2015, 112, 3686-3691.

(12) Wan, L.; Twitchett, M. B.; Eltis, L. D.; Mauk, A. G.; Smith, M. Proc. Natl. Acad. Sci. U. S. A. 1998, 95, 12825-12831.

(13) Sharp, K. H.; Mewies, M.; Moody, P. C.; Raven, E. L. Nat. Struct. Mol. Biol. 2003, 10, 303-307.

(14) Schuller, D. J.; Ban, N.; vanHuystee, R. B.; McPherson, A.; Poulos, T. L. Structure 1996, 4, 311-321.

(15) Vojtechovsky, J.; Chu, K.; Berendzen, J.; Sweet, R. M.; Schlichting, I. Biophvs. I. 1999, 77, 2153-2174.

(16) Lam, S. S.; Martell, J. D.; Kamer, K. J.; Deerinck, T. J.; Ellisman, M. H.; Mootha, V. K.; Ting, A. Y. Nat. Methods 2015, 12, 51-54.

(17) Green, A. P.; Hayashi, T.; Mittl, P. R.; Hilvert, D. I. Am. Chem. Soc. 2016, 138, 11344-11352.

(18) Xiao, H.; Peters, F. B.; Yang, P. Y.; Reed, S.; Chittuluru, J. R.; Schultz, P. G. ACS Chem. Biol. 2014, 9, 1092-1096.

(19) Young, T. S.; Ahmad, I.; Yin, J. A.; Schultz, P. G. L. Mol. Biol. 2010, 395, 361-374.

(20) Yonetani, T.; Iizuka, T.; Waterman, M. R. I. Biol. Chem. 1971, 246, 7683-7689.

(21) Gagliano, R. A.; Knowlton, R. C.; Byers, L. D. I. Org. Chem. 1989, 54, 5247-5250.

(22) Bhagi-Damodaran, A.; Petrik, I. D.; Marshall, N. M.; Robinson, H.; Lu, Y. I. Am. Chem. Soc. 2014, 136, 11882-11885.

(23) Hosseinzadeh, P.; Lu, Y. Biochim. Biophvs. Acta, Bioenerg. 2016, 1857, 557-581.

(24) Lad, L.; Mewies, M.; Raven, E. L. Biochemistry 2002, 41, 1377413781 .

(25) Matsui, T.; Ozaki, S.; Watanabe, Y. I. Am. Chem. Soc. 1999, 121, 9952-9957.

(26) Ozaki, S.; Matsui, T.; Watanabe, Y. L.Am. Chem. Soc. 1997, 119, 6666-6667.

(27) Yonetani, T.; Schleyer, H. I. Biol. Chem. 1967, 242, 1974.

(28) Zhou, M.; Diwu, Z.; Panchuk-Voloshina, N.; Haugland, R. P. Anal. Biochem. 1997, 253, 162-168.

(29) Catalano, C. E.; Choe, Y. S.; Ortiz de Montellano, P. R. I. Biol. Chem. 1989, 264, 10534-10541.

(30) Witting, P. K.; Mauk, A. G.; Lay, P. A. Biochemistry 2002, 41, $11495-11503$.

(31) Aojula, H. S.; Wilson, M. T.; Drake, A. Biochem. I. 1986, 237, 613-616.

(32) La Mar, G. N.; Davis, N. L.; Parish, D. W.; Smith, K. M. L.Mol. Biol. 1983, 168, 887-896.

(33) Yosca, T. H.; Ledray, A. P.; Ngo, J.; Green, M. T. JBIC, I. Biol. Inorg. Chem. 2017, 22, 209-220.

(34) Green, M. T.; Dawson, J. H.; Gray, H. B. Science 2004, 304, $1653-1656$.

(35) Yosca, T. H.; Rittle, J.; Krest, C. M.; Onderko, E. L.; Silakov, A.; Calixto, J. C.; Behan, R. K.; Green, M. T. Science 2013, 342, 825-829.

(36) Makino, R.; Uno, T.; Nishimura, Y.; Iizuka, T.; Tsuboi, M.; Ishimura, Y. L. Biol. Chem. 1986, 261, 8376-8382.

(37) Sitter, A. J.; Reczek, C. M.; Terner, J. L. Biol. Chem. 1985, 260, $7515-7522$.

(38) Sitter, A. J.; Reczek, C. M.; Terner, J. Biochim. Biophvs. Acta, Protein Struct. Mol. Enzvmol. 1985, 828, 229-235.

(39) Yosca, T. H.; Behan, R. K.; Krest, C. M.; Onderko, E. L.; Langston, M. C.; Green, M. T. I. Am. Chem. Soc. 2014, 136, 91249131.

(40) Green, M. T. I. Am. Chem. Soc. 2006, 128, 1902-1906.
(41) Aldag, C.; Gromov, I. A.; Garcia-Rubio, I.; von Koenig, K.; Schlichting, I.; Jaun, B.; Hilvert, D. Proc. Natl. Acad. Sci. U. S. A. 2009, $106,5481-5486$.

(42) Jiang, Y.; Sivaramakrishnan, S.; Hayashi, T.; Cohen, S.; MoenneLoccoz, P.; Shaik, S.; Ortiz de Montellano, P. R. Anoew. Chem. Int. Ed. 2009, 48, 7193-7195.

(43) Onderko, E. L.; Silakov, A.; Yosca, T. H.; Green, M. T. Nat. Chem. 2017, 9, 623-628.

(44) Sivaramakrishnan, S.; Ouellet, H.; Matsumura, H.; Guan, S.; Moenne-Loccoz, P.; Burlingame, A. L.; Ortiz de Montellano, P. R. I. Am. Chem. Soc. 2012, 134, 6673-6684.

(45) Vandemeulebroucke, A.; Aldag, C.; Stiebritz, M. T.; Reiher, M.; Hilvert, D. Biochemistrv 2015, 54, 6692-6703.

(46) Adachi, S.; Nagano, S.; Ishimori, K.; Watanabe, Y.; Morishima, I.; Egawa, T.; Kitagawa, T.; Makino, R. Biochemistry 1993, 32, 241252.

(47) Lin, Y. W.; Wang, J. Y.; Lu, Y. Sci. China: Chem. 2014, 57, 346355.

(48) Lin, Y. W.; Yeung, N.; Gao, Y. G.; Miner, K. D.; Tian, S.; Robinson, H.; Lu, Y. Proc. Natl. Acad. Sci. U. S. A. 2010, 107, 85818586.

(49) Sigman, J. A.; Kwok, B. C.; Lu, Y. I. Am. Chem. Soc. 2000, 122, $8192-8196$

(50) Ayala, M. Redox Potential of Peroxidases. In Biocatalvsis Based on Heme Peroxidases; Torres, E., Ayala, M., Eds.; Springer-Verlag: Berlin, Heidelberg, 2010; Vol. 1, pp 61-77.

(51) Chreifi, G.; Baxter, E. L.; Doukov, T.; Cohen, A. E.; McPhillips, S. E.; Song, J.; Meharenna, Y. T.; Soltis, S. M.; Poulos, T. L. Proc. Natl. Acad. Sci. U. S. A. 2016, 113, 1226-1231.

(52) Berglund, G. I.; Carlsson, G. H.; Smith, A. T.; Szoke, H.; Henriksen, A.; Hajdu, J. Nature 2002, 417, 463-468.

(53) Finzel, B. C.; Poulos, T. L.; Kraut, J. L. Biol. Chem. 1984, 259, 13027-13036.

(54) Matsui, T.; Ozaki, S.; Liong, E.; Phillips, G. N., Jr.; Watanabe, Y. I. Biol. Chem. 1999, 274, 2838-2844.

(55) Ozaki, S.-i.; Matsui, T.; Roach, M. P.; Watanabe, Y. Coord. Chem. Rev. 2000, 198, 39-59.

(56) Carver, T. E.; Olson, J. S.; Smerdon, S. J.; Krzywda, S.; Wilkinson, A. J.; Gibson, Q. H.; Blackmore, R. S.; Ropp, J. D.; Sligar, S. G. Biochemistry 1991, 30, 4697-4705.

(57) Antonini, E.; Brunori, M. Hemoglobin and Myoglobin in Their Reactions With Ligands; North-Holland Publishing Co.: Amsterdam, 1971.

(58) Hiner, A. N.; Rodriguez-Lopez, J. N.; Arnao, M. B.; Lloyd Raven, E.; Garcia-Canovas, F.; Acosta, M. Biochem. I. 2000, 348, $321-$ 328.

(59) Efimov, I.; Parkin, G.; Millett, E. S.; Glenday, J.; Chan, C. K.; Weedon, H.; Randhawa, H.; Basran, J.; Raven, E. L. FEBS Lett. 2014, 588, 701-704.

(60) Delincee, H.; Radola, B. J. Eur. J. Biochem. 1975, 52, 321-330.

(61) Karplus, P. A.; Diederichs, K. Science 2012, 336, 1030-1033.

(62) Murshudov, G. N.; Vagin, A. A.; Lebedev, A.; Wilson, K. S.; Dodson, E. J. Acta Crystallogr., Sect. D: Biol. Crustallogr. 1999, 55, 247255.

(63) Emsley, P.; Cowtan, K. Acta Crystallogr., Sect. D: Biol. Crystallogr. 2004, 60, 2126-2132. 